\title{
TUTELA, CLASSIFICAÇÕES E PRÁTICA DA RENDA INDÍGENA NO RELATÓRIO FIGUEIREDO: ALGUMAS CONSIDERAÇÕES SOBRE PROCESSOS DE DESUMANIZAÇÃO DOS POVOS INDÍGENAS NA GESTÃO DO SERVIÇO DE PROTEÇÃO AOS ÍNDIOS
}

KATIANE SILVA ${ }^{1}$

$U F P A$

VINÍCIUS DA SILVA MACHADO ${ }^{2}$

$U F P A$

GABRIELA GALVÃO BRAVA FURTADO ${ }^{3}$

$U F P A$

ALESSANDRO BALTAZAR RODRIGUES ${ }^{4}$

$U F P A$

RESUMO: $O$ presente artigo tem como objetivo refletir sobre a violência engendrada pelo Estado a partir de modalidades específicas de gestão sobre territórios e populações indígenas, tendo como base as narrativas do Relatório Figueiredo. A ideia principal neste trabalho foi demonstrar como essa violência é concretizada em duas modalidades de controle e gestão: a partir da prática da Renda Indígena e das classificações e categorizações impostas aos indígenas pelo Serviço de Proteção aos Índios (SPI), de modo a inferiorizá-los e estabelecer relações assimétricas de poder vigentes ainda hoje na sociedade.

PALAVRAS-CHAVE: povos indígenas; Relatório Figueiredo; violência.

ABSTRACT: This article aims to reflect on the state-generated violence from specific management modalities on indigenous territories and populations, based on the stories of the Figueiredo Report. The main idea in this work is to demonstrate how this violence is accomplished in two modalities of control and management: from the practice of indigenous income and the classifications and categorizations imposed on indigenous people by the Indian Protection Service (SPI), in order to subdue them and establish asymmetric power relations, which are still operating in society.

\footnotetext{
${ }^{1}$ Docente no Programa de Pós-graduação em Antropologia (PPGA) na Faculdade de Ciências Sociais (FACS) da Universidade Federal do Pará (UFPA).

${ }^{2}$ Discente do Programa de Pós-graduação em Antropologia da UFPA, bacharel em Direito pela mesma instituição. Coordenador da seção norte (2016/2017/2018) do Instituto de Pesquisa em Direitos e Movimentos Sociais.

${ }^{3}$ Discente do curso de Ciências Sociais da UFPA, bolsista PIBIC PRODOUTOR (IC) 2017.

${ }^{4}$ Discente do curso de Psicologia da UFPA, bolsista PIBIC-AF (IC) 2017.
} 


\section{Introdução}

A proposta deste texto é refletir sobre a violência engendrada pelo Estado a partir de modalidades específicas de gestão sobre territórios e populações indígenas, tendo como base empírica o Relatório Figueiredo (doravante RF). A ideia principal neste trabalho foi demonstrar como essa violência é concretizada em duas modalidades de controle e gestão: a partir da prática da Renda Indígena e das classificações e categorizações impostas aos indígenas pelo Estado - na figura do Serviço de Proteção aos Índios (SPI) -, de modo a inferiorizá-los e estabelecer relações poder assimétricas vigentes ainda hoje na sociedade.

O RF foi produzido em 1967 pelo procurador Jáder de Figueiredo Correia, nomeado pelo então ministro do interior Albuquerque Lima, por meio da Portaria $\mathrm{n}^{\circ} 239$ de 1967, para apurar as denúncias de irregularidades ocorridas no SPI. O Relatório é composto por um conjunto de documentos, inquéritos e relatos contendo mais de 7.000 páginas. Para a produção deste artigo, nosso trabalho consistiu na leitura da síntese do relatório e dos volumes 1, 3 e 20.

A partir da leitura destes volumes, procuramos contextualizar e compreender os efeitos sociais desse processo de genocídio e violação de direitos indígenas durante a ditadura, e suas implicações no contexto atual. Segundo Jean Bazin (2008), a tarefa do antropólogo é tentar descrever situações e o espaço dos possíveis, onde os atores sociais se movem de uma situação a outra, num contexto histórico dado. Nesse sentindo, procuramos, a partir das informações trazidas no RF, compreender pela prática dos relatos as sequências de ações ao longo desse processo histórico de violências e violações de direitos, e não um mero inventário descritivo desses povos ou das dores sofridas pelos indígenas. De modo algum pretendemos fetichizar o RF em si e criar outras situações de violência a partir da reificação de uma ideia de alteridade radical. 
O RF é um documento marcado por contradições, e a própria inclusão dos indígenas na empreitada da Comissão Nacional da Verdade revela as dificuldades do Estado em reconhecer a violência cometida ao longo da história, mais especificamente, no período da ditadura. Durante décadas, acreditou-se que o relatório tivesse sido destruído por um incêndio no ministério da agricultura em junho de 1967, mas ele foi redescoberto em novembro de 2012 pelo pesquisador Marcelo Zelic, no Museu do Índio, no Rio de Janeiro (AZOLA; LIMA, 2017).

A tentativa de classificar os indígenas e a instituição do trabalho forçado (dentre outras situações) pela "Renda Indígena" também se configuram como continuidades das práticas de colonização enquanto "um vício antigo, não como uma atitude inédita" (MATTEl; NADER, 2013, p. 27), no qual o Direito tem sido usado para justificar e administrar o que os autores chamam de pilhagem. Neste processo, os mais fracos são submetidos por agentes políticos que chegam a terceirizar a prática da espoliação.

A partir da leitura contextualizada do RF, foi possível observar como a violência, enquanto uma construção histórica e cultural, está imbrincada nas diversas modalidades de "gestão de populações" (Foucault, 2001), de modo que não se governa um estado, um território ou uma estrutura política, mas sim o governo se impõe sobre as pessoas, os homens, os indivíduos ou coletividades. Essa concepção de gestão e governo de populações disciplina e modifica o espaço, impõe modos de viver e cria estereótipos a respeito dos povos indígenas, bem como reforça a ideia principal do projeto de nação: civilizar regiões consideradas inóspitas e habitadas por tipos que não correspondiam ao modelo de nação brasileira.

\section{O Relatório Figueiredo: denúncia e tentativa de "moralização" do SPI}

O Relatório Figueiredo é apresentado como o resultado de uma investigação empreendida pelo procurador Jáder de Figueiredo Correia ${ }^{5}$ a

\footnotetext{
${ }^{5}$ Conforme Valente (2017), Jáder tinha ligações fortes com militares e políticos, como o ex-governador do Ceará, Virgílio Távora, e atuou em sintonia com o Ministério do Interior e com o Serviço Nacional de Informações (SNI).
} 
pedido do ministro do interior Afonso Augusto de Albuquerque Lima por meio da portaria $n^{\circ} 154 / 67$, a qual constituiu a Comissão de Inquérito (Cl) para cumprir o que preceitua a lei e indiciar os culpados e fora instalada no dia 3 de novembro de 1967, em plena ditadura civil e militar. O objetivo do documento visa apresentar violações cometidas por funcionários do Serviço de Proteção aos Índios (SPI), órgão subordinado ao Ministério da Agricultura, contra indígenas brasileiros ao longo das décadas de 40, 50 e 60 do século XX, mediante provas documentais e testemunhais.

O relatório denuncia roubo de recursos do patrimônio indígena, venda irregular de gado, madeira, extração ilegal de minérios, arrendamento criminoso de terras a todo tipo de violências contra a pessoa do índio, tais como assassinatos, prostituição, sevícias, trabalho escravo, torturas, massacres e genocídio. As investigações iniciaram em 1967, com a comissão percorrendo parte do território nacional, entrevistando dezenas de agentes do SPI, e visitando diversas aldeias de um total de cinco, das nove Inspetorias Regionais. (GUIMARÃES, 2015, p.13)

$\mathrm{Na}$ síntese do relatório, são apontados de maneira sucinta os percursos da investigação e a sua abrangência. Nesse período, o SPI, fundado em 1910, operava com 130 postos indígenas, espalhados por 18 estados da federação e atuando em quase a totalidade do território brasileiro, enraizado de forma interiorizada. A comissão, em uma investigação de fôlego, percorreu mais de 16 mil quilômetros.

Embora a narrativa de Jáder no relatório possa indicar, ao primeiro olhar, um tom de indignação e empatia com os indígenas, é necessário compreender que seu principal objetivo era "moralizar" o SPI - uma instituição cuja razão de ser se pautava na proteção tutelar dos indígenas. Tratava-se, antes, da denúncia aliada à continuidade da "prática da política de integração nacional" (SOUZA LIMA, 2011), concebida pelo regime militar.

Para fins de explicação, o documento produzido pela comissão de inquérito aponta que não conseguiu precisar a totalidade de violações e nem levantar com exatidão o valor necessário para a devida reparação dos danos cometidos aos povos indígenas, pois a área de jurisdição do SPI era vasta e o número de membros disponibilizados para a comissão 
não acompanhou, proporcionalmente, o tamanho da tarefa. Dessa feita não foi possível apresentar "perfeito trabalho de apuração" (BRASIL, 1967, fls 12), quer quantitativamente, quer qualitativamente.

Entretanto, tais limitações não foram empecilho para constatar a depravação em curso dentro do SPI. Com as provas colhidas, ao longo do processo de investigação, foi possível afirmar que as irregularidades encontradas são suficientes para considerar o órgão como o maior escândalo administrativo do Brasil, sendo antro de corrupção e barbárie inominável durante muitos anos.

Foram várias as atrocidades perpetradas pelos agentes do Estado brasileiro, crimes que devastam material e imaterialmente os povos indígenas. O relatório coloca de forma explícita a desumanização dos funcionários do SPI em sua atuação. São descritos alguns desses terrores como: crucificação, estupros, venda de crianças, roubo de produção, açoite no tronco, venda de terras, desvio de verbas, humilhações públicas, constituição de polícia indígena ou capitão indígena, tortura, espancamentos, obrigar pessoas a castigar os seus entes queridos, cárcere privado, trabalho escravo, entre outras atrocidades.

Essa gama de perversidades cometidas foi categorizadas em vários crimes e apresentada em um rol exaustivo que segue: (1) crimes contra a pessoa e a propriedade do índio: (1.1) assassinato de indígenas (individuais e coletivos), (1.2) prostituição de indígenas, (1.3) sevícias, (1.4) trabalho escravo, (1.5) usurpação do trabalho indígena, (1.6) dilapidação do patrimônio indígena: venda de gado, arrendamento de terras, venda de madeira, exploração de minérios; (2) adulteração de documentos oficiais; (3) fraude em processo de comprovação de contas; (4) desvio de verbas orçamentarias; (5) aplicação irregular de dinheiro público; (6) omissão dolosa; (7) admissão fraudulenta de funcionários; (8) incúria administrativa.

Esses crimes são relatados na síntese do relatório, em que também é apresentado o esquema que sustenta a sua efetivação, colocando de que forma essas manobras criminosas eram desenvolvidas no seio do SPI e como os seus funcionários, desde a diretoria geral até os ocupantes dos postos avançados, executavam essas barbaridades contra os povos indígenas. 
Todos os fatos descritos foram verificados durante as visitas aos postos de atuação do SPI, aos gabinetes regionais e nacional. O roteiro das inspeções era mantido sobe sigilo; contudo, ocorria vazamento de informações e postos eram avisados com alguma antecedência e tentavam mascarar as atrocidades, mas obtinham pouco êxito nesse intento, pois não era possível mascarar tudo. A miséria continuava imutável, a carne estava exposta e o sangue regava a terra.

Como resultado do inquérito, o relatório indicou 132 pessoas a serem indiciadas e prestarem conta dos seus crimes. Tudo comprovado com provas e essas foram juntadas ao documento finalizado com mais de sete mil páginas, dividido em 30 tomos. O relatório contribui para a substituição do SPI pela Fundação Nacional do Índio (FUNAI), criada como órgão do Ministério do Interior em 1967.

É inegável a importância do relatório Figueiredo e a sua validade, contudo, em suas páginas os povos indígenas são apresentados como indefesos, amedrontados, silvícolas incapazes de lutar contra o maquinário social colonialista desenvolvido pelo Estado brasileiro na consubstanciação denominada de SPI. É importante relatar essa lacuna do documento, que não aponta como os povos indígenas se organizaram para lutar contra o etnocídio e genocídio, e quais agências foram utilizadas nesse combate. É impossível imaginar que, nesse processo conflituoso, os povos indígenas não tenham construído estratégias de combate e resistência a essa política indigenista. É necessário buscar essa outra parte da história para ser possível compreender de maneira mais alargada a atuação do SPI nesse período.

Esse documento tem uma dupla importância, muito valiosa para a sociedade brasileira, a partir de suas denúncias. Primeira, é uma chave que pode abrir as portas para uma nova sociedade mais plural, que reconheça a diversidade e veja nela uma forma de ressignificar velhas práticas; a segunda diz respeito ao quadro registrado nas páginas desse artefato oficial, uma imagem que não nos deixa esquecer das atrocidades cometidas contra os povos indígenas, informações que nos lembram de não cometer os mesmos erros. 


\section{Violência e classificações: a tutela do Estado no processo de humanização e desumanização dos povos indígenas}

Diversas estratégias de classificação dos índios em documentos oficiais foram produzidas em momentos históricos diferentes e aparentemente não possuem relação estreita. Contudo, o esforço para relacioná-las pode ser imprescindível para perceber o que está em jogo no quadro característico das políticas institucionais para controle do território nacional: integrar determinada população de modo a explorar sua força de trabalho.

Analisar os processos de classificação ou produção de imagens preconcebidas atribuída aos povos indígenas pode ser um exercício importante na compreensão das políticas indigenistas do SPI. Expressões e categorias como aculturação, caboclo, tribo, assimilação podem ser problematizadas num contexto onde a normatividade da política indigenista atribui identidades aos povos indígenas, criando-se efeitos ou marcas para diferenciar as vidas dessas pessoas, além de representações positivas ou negativas.

Podemos pensar, a princípio, em dois esquemas de representação sobre os indígenas presentes no RF: vítimas/indefesos ou irracionais. Discutir sobre a violência na construção de uma alteridade extrema e da exotização dos povos indígenas ao longo do tempo também é importante para a compreensão dos efeitos sociais desses processos nos dias atuais. O antropólogo francês Jean Bazin (2008) observa que a imagem concreta do "outro", enquanto inimigo a ser combatido, se constitui a partir do estabelecimento do léxico e da gramática de uma etiqueta cultural totalizante e, consequentemente, violenta.

Neste sentido, é importante trazer para a discussão a ideia de Butler sobre a violência, pois

já há certa violência quando somos remetidos a um discurso, nomeados, submetidos a uma série de imposições, compelidos a responder a uma alteridade exigente. Ninguém pode controlar os termos segundo os quais o discurso nos é remetido, pelo menos não em sua forma mais fundamental. Ser submetido ao discurso é, já de início, ser despido de vontades e sentir esta privação como a base de sua própria situação no discurso (BUTLER, 2011, p. 23). 
É possível perceber no material apresentado no Relatório o modo como o Estado, na figura do SPI, se constitui como um desses segmentos que instaura essa gramática da exclusão social. A violência aqui pode ser compreendida a partir da definição de Blok (2001), que entende a violência como experiência ou como uma espécie de reverso da ordem social. A violência é irracional, é uma anomalia, é a antítese da civilização. A partir dessas afirmações, é possível formular a seguinte pergunta: como o Estado, que tem como uma das funções administrar populações a partir da premissa da racionalidade, pôde, sistematicamente, exercer diversas atividades extremamente violentas contra os povos indígenas? A caracterização geral que o presidente da CPI traz sobre os indígenas consiste num quadro desolador:

De maneira geral, não se respeitava o indígena como pessoa humana, servindo homens e mulheres como animais de carga, cujo trabalho deve reverter ao funcionário. No caso da mulher, torna-se mais revoltante porque as condições eram mais desumanas. Houve postos em que as parturientes eram mandadas para 0 trabalho dos roçados um dia após o parto, proibindo-se conduzirem consigo o recém-nascido. (Síntese, RF, p. 4914)

Norbert Elias (1997), ao tratar dos processos de pacificação da sociedade alemã, diz que a civilização propriamente dita e sua racionalidade estão sempre ameaçadas. A principal característica do processo civilizador é a mudança na relação entre coações sociais externas e autocoações individuais. Nesse sentido, a suposta pacificação interna, num projeto de nação, está sempre em risco devido aos conflitos sociais que fazem parte da sociedade. É justamente por isso que as instituições pacificadoras têm interesse em dominar os conflitos, e este domínio pode ser inscrito nas relações, nos corpos e nas almas. É neste sentido que a vida social e a pacificação dentro do Estado, sob o ponto de vista deste autor, estão baseadas na violência.

O SPI, cujo primeiro diretor foi Cândido Rondon, tinha como principal objetivo e metodologia atrair e pacificar os grupos indígenas para tutelá-los e transformá-los no que se entedia como mão de obra para o Estado. Teoricamente, este seria o primeiro órgão estatal e laico, 
dedicado integralmente aos indígenas e, portanto, ofereceria condições para inseri-los no chamado processo civilizatório, seguindo a ideia positivista da "ordem e progresso" estampada na bandeira do Brasil.

O SPI surgiu como resposta aos inúmeros conflitos
resultantes de mais uma vaga de ocupação e exploração
territorial em diversos pontos do país, dentro dos
quadros de um Estado em expansão e de atividades
econômicas que penetravam em regiões ocupadas por
povos indígenas em estado de guerra contra seus
invasores. Na contramão do discurso fundador do SPI,
busquei pensar as ações governamentais sobre os
indígenas não apenas como demonstração de bondade e
generosidade, forma abnegada de proteger aquele que é
tomado como incapaz de participar plenamente numa
comunidade política, como ato humanitário, mas
também de inseri-las como parte dos processos de
formação de Estado, de extensão de sua malha
administrativa através da articulação de âmbitos
domésticos e públicos, de uso do trabalho indígena e,
mais importante, de liberar terras aos interesses
econômicos de grupos privados (SOUZA LIMA, 2015, p.
4).

O processo de tutela no SPI se efetivou por meio da lei $\mathrm{n}^{\circ}$ $5485 / 1928$ do artigo $6^{\circ}$ do Código Civil, que institui o índio enquanto status jurídico sem, porém, defini-lo, tarefa deixada ao cotidiano da administração (SOUZA LIMA, 2011). Para o SPI, tutelar era sinônimo de civilizar. Assim, utilizaram técnicas de atração, visando conquistar a confiança desses povos para que fossem fixados em postos onde seriam educados e preparados para o trabalho com a terra.

A criação do SPI se deu seguindo o objetivo de Cândido Rondon, que apresentou à nação o modo de vida dos índios e demostrou que era possível "civilizá-los" sem o uso de armas, mas utilizando um conjunto de técnicas de atração e pacificação de povos hostis, utilizada no período colonial pelos jesuítas (SOUZA LIMA, 2011). Seu lema era, "morrer, se preciso for; matar, nunca", frase que possibilitou um certo "heroísmo". Porém, defender Rondon é louvar o Estado brasileiro. E transformar os indígenas em trabalhadores rurais e não matá-los traduzia-se em um doce etnocídio, no lugar de um cruento genocídio (SOUZA LIMA, 2011). Rondon "mostrou à nação o modo de vida dos indígenas e demostrava 
que era possível civilizá-los pela persuasão sem o concurso de armas" (SOUZA LIMA, 2011 , p 206).

A política de Rondon assegurava a preservação de seus usos e costumes "primitivos", desde que vivendo sob a proteção dos agentes do Estado brasileiro. Os índios eram vistos como representantes de um estágio mais primitivo da humanidade, portanto incapazes de sobreviver aos avanços da sociedade moderna sem escapar do extermínio, sendo uma obrigação do estado protegê-los e permitir que se adaptassem ao mundo contemporâneo (OLIVEIRA FILHO, 2014). A tutela se dava pela perda da autonomia e pela atribuição a um grupo o poder de falar e agir no lugar do outro, de modo que era negada até a possibilidade de falar.

Assim, embora os programas governamentais muitas vezes definam metas a serem cumpridas e benefícios a serem recebidos pelas populações tuteladas, na realidade o que é fielmente executado são as ações repressivas e de controle, em geral de interesse de terceiros, as demais raramente saindo do papel" (OLIVEIRA FILHO, 2014, p. 146).

Dentro deste processo de tutela indígena, é importante destacar a ignorância do governo militar, já que após o golpe não se sabia ao certo quantos índios viviam no Brasil. Apenas conhecia os aldeados, que estavam em terras demarcadas, sobre o controle da União,

alcançados ao longo do século por atividades de desenvolvimento econômico e ocupação dos solos, fazendo as pazes com o homem autodenominado civilizado, aceitando a derrota para tentar sobreviver em um novo mundo com novas regras" (VALENTE, 2017, p. 9).

Havia muitos mais vivendo dentro das matas, e o baixo registro oficial não pode explicar como a ditadura militar tratou os indígenas. Desta forma, assinalo a importância na compreensão da tutela que foi imposta aos indígenas, pois estava a mercê de um estado que tinha a intenção de proteger, mas que acabou por violar os seus direitos.

Davis (1978) afirma que o SPI "correspondeu aos ideais pacifistas de Rondon" (p. 26) no seu período inicial, de acordo com Darcy Ribeiro. Para o autor, "durante 20 anos, nenhum índio foi morto ou ferido por indigenistas, embora muitos destes tenham morrido". Contudo, ele 
também destaca que a tentativa de mediação do SPI entre os indígenas e a "sociedade envolvente" não foi bem-sucedida, já que "em quase todas as áreas onde o SPI funcionava, os índios foram varridos pelas doenças ou tornaram-se populações marginalizadas em minúsculas parcelas de terra" (p. 27).

Um exemplo dessa razão de ser pacificadora, a partir da ideia de um grande cerco de paz proposta por Souza Lima (1992), pode ser observado na atuação do SPI na Amazônia ( $1^{\text {a }}$ Inspetoria Regional) em seus primeiros anos, destacada por Freire (2009):

O Ministério da Agricultura, Indústria e Comércio identificava Rondon como o militar que havia se dedicado a "resolver" o "problema indígena", definido como a necessidade de pacificação de "índios bravios". A "guerra contínua" destes como os "civilizados" seria enfrentada em duas frentes, envolvendo as atividades do SPI e da Comissão de Linhas Telegráficas Estratégicas de Mato Grosso ao Amazonas.

O processo de pacificação adotado pelo SPI era qualificado pelos seus diretores como excelente, de "absoluta eficácia" diante de exemplos históricos. O SPI associava a pacificação com a sedentarização do indígena e o consequente avanço dos "civilizados". Era a "abertura dos sertões à iniciativa dos particulares", que transformava "em pouco tempo paragens selváticas em lugares beneficiados pela civilização" (FREIRE, 2009, p. 31).

O "avanço dos civilizados" às terras indígenas estava aliado a outra ação violenta a ser considerada no processo de pacificação: descaracterizar os povos indígenas por meio da força da imposição de categorias classificatórias. $O$ ato de classificar é operacionalizado por meio de conceitos chave para a antropologia: raça, etnicidade e nação. Esses conceitos estão, em princípio, relacionados ao ato de ordenar hierarquicamente indivíduos ou grupos considerados minoritários. Esta é uma discussão em que a produção dos saberes sobre a biologia e a cultura também foi utilizada para, basicamente, demarcar e impor a existência cristalizada destes grupos num contexto nacional mais amplo. Um dos pressupostos do estado-nação é o reconhecimento de dados indivíduos enquanto pertencentes ao conjunto de características determinadas como nacionais. 
A esse processo de integração forçada dos indígenas à sociedade nacional por meio da pacificação, associamos, dentre outras estratégias, a educação. Alípio Bandeira, militar e primeiro chefe da inspetoria do Amazonas, elaborou um documento que avaliava a legislação indígena, defendendo a assistência e proteção leiga e elaborando uma classificação dos indígenas do Amazonas, tendo sido divididos em quatro categorias:

a. Os selvagens, que não têm relações com os civilizados.

b. Os selvagens que já receberam violências do civilizado.

c. Os que, já estando domiciliados na civilização, formam sociedade à parte.

d. Os que vivem em inteira promiscuidade com civilizados.

Os da primeira classe são a seu modo moralizados, trabalhadores e bem reputados. Tratam com muita hospitalidade os raros civilizados que por acaso chegam às suas terras, mantendo-se, todavia, em uma prudente reserva.

Os da segunda classe têm fama de ferozes mas, de fato, são apenas defensores da sua liberdade e da honra de suas famílias. São também trabalhadores e tão moralizados quanto lhes permite sê-lo o atraso mental em que vivem.

Os da terceira classe já não têm mais as qualidades de caráter dos outros nem são também tão trabalhadores como eles.

Os da quarta classe são uns infelizes cheios de vícios e defeitos dos quais o menor é talvez a preguiça.

Conclui-se do exposto quanto mais afastados estão da civilização madrasta, melhores e mais assimiláveis à sociedade são os índios, e quanto mais ligados a ela menos suscetíveis de aproveitamento.

Vê-se pois, que a desmoralização é um produto da educação que recebem, à qual, como crianças, fácil e francamente afeiçoam. Tudo mostra que sendo ela boa os índios selvagens progredirão moral, intelectual e praticamente. (BRASIL, 1911 apud FREIRE, 2009).

A compreensão sobre a imposição de um "caráter do índio" brasileiro e da gestão dessas populações como um problema a ser resolvido corrobora a produção ideológica do SPI. Ao longo do processo de colonização brasileira, os indígenas necessitaram praticar uma espécie de ocultação do que se entendia como suas culturas enquanto estratégia 
de resistência às violências e às imposições no que se refere às perdas forçadas - como a língua, os conhecimentos estéticos e de manejo do meio ambiente, as afetividades e as cosmologias.

É muito presente no RF o empenho do Estado em inserir os povos indígenas no contexto nacional, para o qual é necessária uma espécie de perda cultural para a introdução do papel "trabalhador nacional". Oliveira (2004) critica a concepção de perda cultural - que de certo modo observamos na descrição proposta por Alípio Bandeira - evidenciada na "avaliação negativa quanto às perspectivas de uma etnologia dos povos e culturas indígenas do Nordeste", por exemplo, cultivada tanto na etnologia quanto no indigenismo. O fatalismo da extinção dos nativos era um tema constante na literatura do século XIX e que, de certo modo, se estendeu ao século XX. Essas concepções disciplinam e modificam o espaço, impõem modos de viver e criam estereótipos sobre os indígenas, bem como a ideia de um índio genérico.

Compreender como os povos indígenas foram submetidos ao Serviço de Proteção aos Índios (SPI) nos permite traçar uma lista histórica para melhor entendimento de como ocorreu o processo de tutela indígena - termo abordado no Relatório Figueiredo, que caracterizou o índio como tutelado do governo brasileiro.

A questão da tutela é a chave de análise deste processo. O Brasil no período colonial, por meio do Direito Romano, que definia no título 102 do Livro IV, originalmente associava a tutela exclusivamente aos órfãos, a qual se constituía no encargo de administrar a pessoa e os bens de um menor, imposto pela lei ou pela vontade dos homens (SAMPAIO, 2014). Assim, a tutela foi arbitrada e acompanhada pelo Juízo dos Órfãos, instância judicial longeva que, em 1731, foi implantada em nível municipal na América Portuguesa (SALGADO, 1935). A administração das populações indígenas também foi atribuída ao Juízo dos Órfãos. Contudo isso não era pertinente, pois não eram órfãos e sim donos de suas terras, línguas e culturas. Para adequá-los ao Juízo de Órfãos, classificou-se a "recusa do trabalho" forçado como "demência" (CUNHA e FARAGE, 1987).

Discutir sobre classificação e identidade implica também apresentar a questão da fricção interétnica relatada por Roberto Cardoso de Oliveira (1996), que elabora um debate importante acerca do contato entre indígenas e não indígenas, apoiado na ideia do conflito. $O$ índio era 
visto como um problema nacional e uma ameaça, o que alimentava a desconfiança e o medo das pessoas não indígenas. E, para o índio, as alternativas possíveis se reduziam à defesa armada ou à ressignificação do estilo de vida que a chamada "civilização" Ihe impõe. Esse atrito entre índios e civilizados agravara as relações. É percebível que, a partir desse contato, a identidade indígena estava à mercê de uma série de mudanças, mesmo na tentativa de defender suas condições étnicas.

As narrativas oficiais sobre a construção de uma nação brasileira contribuíram com o resultado do processo de inferiorização do indígena como um Outro primitivo e passível de ser civilizado. Assim, há também uma violência histórica do Estado, a qual destaco a primeira constituição do Brasil independente, em que não foi possível incluir os povos indígenas, pois, na época não eram considerados humanos, não sendo, portanto, sujeitos de direitos (BRIGHENTI, 2015). As terras que essas populações ocupavam despertaram interesse da oligarquia, provocando a extinção de aldeamentos e intensificando o processo de tutela. Assim, a política adotada pela instituição tinha como objetivo principal civilizar os indígenas e transformá-los em trabalhadores nacionais.

Há ainda a refletir a despesa que se faz em postos de índios já quase que completamente civilizados. Não se admite, por exemplo, posto indígena no Estado de São Paulo, porque o contato dos índios com a civilização isso acontece em Mato Grosso - já lhes dá plena capacidade, de maneira a conseguir sua emancipação, devendo por isso o SPI tratar de aproveitar melhor e racionalmente estas reservas em benefício do próprio índio. Conheço lá no meu Estado, na região de Aquidauana e Miranda, os postos indígenas Limão Verde, Cachoeirinha, Ipegue e Bananal. Em nenhum deles existe índio que se possa dizer que esteja em estado semi-civilizado. São todos índios completamente civilizados, índios que leem, que escrevem, que são eleitores (Depoimento do deputado Edison Garcia, em 25/04/1963. RF, v. 1, p. 106).

A expectativa da eficácia do projeto nacional de civilização é sempre presente nos discursos de alguns depoentes. Embora conhecendo as experiências trágicas da pacificação empreendida pela instituição, espera-se que esse representante do "mundo natural" ou irracional seja incorporado à racionalidade burocrática da máquina estatal. 
Nobre Deputado Antônio Brezolin, sou contra o sistema até então vigente no SPI, de considerar o índio um espécime da nossa fauna. O índio é homem como outro qualquer, adaptável à civilização como qualquer um. Haja vista o fato de, nas reservas indígenas do Sul do Estado, eu não encontrar um só que não produza como qualquer outro trabalhador. No município de Aquidauana, tôdas as fazendas se abastecem entre os índios, que prestam serviços como outro brasileiro qualquer. Praticam a agricultura nas reservas mais próximas e nos centros urbanos, a que aprenderam com os civilizados, é claro, mas praticam. (...) acho que a melhor política a adotar pelo SPI seria a de aproveitar, e já, racionalmente, as reservas, com os índios, ou mesclá-los com os civilizados. Uma boa oportunidade de melhorar o índice de civilização do índio, através dêsse trabalho ordenado, racional, de aproveitamento das terras e não deixando que o índio continue pescando e caçando, como na época do descobrimento do Brasil (Depoimento do deputado Edison Garcia, em 25/04/1963. RF, v. 1, p. 112)

De acordo com o depoimento, por ocasião da CPI de 1963, de José Fernando da $\mathrm{Cruz}^{6}$, ex-inspetor da $5^{\mathrm{a}}$ Inspetoria, e que na ocasião se encontrava no cargo de inspetor da $1^{\mathrm{a}}$ Inspetoria, a prática do trabalho nos Postos Indígenas exigia atitudes muitas vezes questionáveis. Ao ser indagado pelo deputado Valério Magalhães a respeito do fornecimento de armas para proteção dos indígenas das represálias de fazendeiros, o inspetor dá destaque a mais um tipo de representação e classificação sobre os indígenas:

O Regimento do SPI determina que o Chefe da Inspetoria é responsável pela manutenção da posse da terra, dos costumes e do respeito às tribos indígenas. Dentro da própria reserva foi assassinado um índio. Pedimos tôdas as, digo, tôdas as providências cabíveis e legais para prender o criminoso. Também não houve nenhuma providência. Houve um verdadeiro tumulto nessa época em Campo Grande. V. Exa. não pode imaginar como se formou o ambiente de tensão, de nervos, com relação a êsse fato. Os índios fugiram e localizaram-se na mata.

\footnotetext{
${ }^{6}$ Foi acusado dos seguintes crimes: esbulho do patrimônio indígena; cheque sem fundo; indiciado por homicídio; abuso de autoridade; perjúrio. (BRASI, 1967). Segundo Guimarães (2015), "Fernando Cruz é um funcionário polêmico. Ele é reconhecido pela sua dedicação aos índios, e é um dos poucos chefes que denunciam irregularidades e crimes, no âmbito do Serviço, às autoridades competentes” (p. 89).
} 
Então para que eu pudesse ter um sôbre eles, para evitar que êles atacassem fazendas, fizessem violências e praticassem depredações nas fazendas, fui lá e disse a êles que não havia perigo, que ficassem calmos que nós garantiríamos. (...) Sr. Presidente, a maneira de nos entendermos com o índio é um tanto fora do normal, porque é um homem que não tem a nossa evolução intelectual. Temos de nos entender com êles mais com atos do que com palavras. Porque, se formos analisar bem a vida do nosso Serviço, em cinquenta e dois anos o índio não está sendo realmente assistido. Pacificamos o índio e o entregamos à desgraça, à miséria, porque a terra é invadida (Depoimento de José Fernando da Cruz, em 14/05/1963. RF, v. 3, p. 435-6, grifo nosso)

No Relatório Figueiredo o índio é classificado como "indefeso" que ao mesmo tempo é "selvagem" ou ameaça para a sociedade, e é preciso destacar como o SPI pensava isso e de que forma se deu o uso dessas palavras marcadas com um grande processo de inferiorização do outro. O discurso do evolucionismo sempre atravessa os depoimentos, mesmo quando se trata do ataque direto a uma tomada de decisão de um funcionário do SPI. "As categorias, por mais que restrinjam os seus significados ao uso no tempo presente, estão marcadas por atitudes e conotações que remetem às instituições e expectativas do passado" (OLIVEIRA, 2014, p. 125). Assim, o principal questionamento é assinalar o índio que deixou de ser selvagem para se tornar indefeso. Podendo, assim, discutir sobre as consequências que a tutela causou por meio da pacificação.

O método adotado pela expedição era o mesmo das outras feitas no país desde os tempos do marechal Cândido Rondon (1865-1958). Criava-se uma frente de atração, que funcionava assim: os sertanistas distribuíam presentes aos índios; esperava-se que estes passassem a retribuir os presentes, na fase chamada de namoro; na terceira fase, os índios convidavam os sertanistas para conhecer suas malocas; a quarta fase, de consolidação de "pacificação", constituía-se no estabelecimento de um acordo pelo qual, em resumo, "civilizados" e índios concordavam em não matar mais uns aos outros (muitas vezes esse diálogo não era feito às claras, pois os índios praticamente se entregavam aos benefícios representados pelos presentes dos "civilizados" da Funai); por último, os índios 
"pacificados" eram então agregados e entregues aos cuidados de funcionários de um posto, que se encarregava de dar a eles atendimento de saúde e alimentação e ensinar-lhes métodos de agricultura dos "civilizados". Assim, os índios deixariam de atacar e matar vizinhos ou trabalhadores que passavam pela região. Estava criado um novo posto indígena para índios aldeados (VALENTE, 2017, p. 14).

Ao tratar o índio como selvagem, o SPI o coloca em uma condição irracional em uma sociedade que dava importância aos valores da ordem. Transformar esse selvagem em indefeso é dizer que é uma criança, que precisa de educação e proteção; domesticá-lo e civilizá-lo, e assegurar que fosse integrado como cidadão brasileiro que almeja apenas o progresso. Todavia, essa ideia causou a perda de identidade indígena em todos os sentidos.

Em depoimento ao então presidente da CPI de 1963, deputado Valério Magalhães, o funcionário do SPI, Walter Samari Prado, comenta que a instituição não está apta a integrar o indígena à sociedade, apontando o que parece um consenso geral:

O SR. PRESIDENTE - o SPI em rigor, não procura chamar o índio à civilização. Não é só domesticá-lo: é trazê-lo para ser elemento útil à sociedade. O SR. DEPOENTE Não basta somente domesticar o índio, trazê-lo para o nosso convívio, porque devíamos antes pacificá-los criar condições para a subsistência dêles. O SR. PRESIDENTE - Decerto. Mas desde que esteja pacificado, o SPI não promove sua integração na comunidade nacional, pois que até êsses princípios básicos de como trabalhar a terra, os mais rudimentares possíveis, o SPI não lhes dá. O SR. DEPOENTE - Exato. O SR. PRESIDENTE - É, consequentemente, uma domesticação como de qualquer animal. A anta é animal que, domesticado, fica conosco dentro de casa, anda no quintal, passa a comer em nossas mãos, mas não entra para a civilização. O SR. DEPOENTE - Tem sido assim. E se não houver modificação nesse sistema, a tendência é desaparecer o índio, que não tem nossa resistência física. (Depoimento Walter Samari Prado, em 06/06/1963. RF, v. 3, p. 513514).

Um dos pontos que chamam atenção neste trecho é a metáfora utilizada para representar o trabalho do SPI: a comparação entre a 
domesticação de um animal, a anta, e a domesticação do índio. O sentido de pacificação trazido no depoimento destaca a diferença entre domesticar e pacificar. É justamente este olhar colonizador do Estado sobre os indígenas que institui o sinônimo de abjeção à diversidade indígena, também abrindo precedentes às práticas de tortura empreendidas em diversas inspetorias e momentos.

Nesse sentido, é possível observar a gradação entre o que se considera mais ou menos humano. Quem detém a auto representação tem mais chances de ser humanizado, observa Butler (2011), apoiada em Levinas, e quem não tem a oportunidade de se representar é tratado ou visto como menos humano ou mesmo invisibilizado. É por isso que classificar os indígenas como tutelados, pacificados, semicivilizados, em vias de civilização, caboclos, selvagens, dentre outras categorias, pode ser considerado um ato de desumanização, que viabiliza a tortura. No depoimento de Samuel Brasil, outro funcionário da $7^{\mathrm{a}}$ Inspetoria do SPI, ele informa que ao assumir a chefia do Posto Manoel Ribas,

Encontrou índios aleijados por torturas no "TRONCO", aparelho utilizado ao tempo da escravatura do Brasil e revivido no SPI; que o "TRONCO" consiste em duas estacas enterradas em angulo agudo no mesmo buraco do vértice para baixo; que existe em cada uma delas um pequeno entalhe de altura correspondente; que a tortura consiste em colocar o tornozelo do índio entre as duas estacas à altura daqueles entalhes, insuficientes paca digo, para caber uma perna humana, e paulatinamente fechar o angulo aproximando as duas pontas superiores das estacas com o auxílio de uma corda; que isso é um processo muito doloroso e se levado a extremo poderá provocar a fratura do osso, como aconteceu no caso, muitas vezes; que a Comissão poderá encontrar ainda naquele Pôsto Manoel Ribas índios aleijados por essa tortura; que o depoente desarmou e baniu aparelho de tamanha atrocidade; (...) que ACIR BARROS [funcionário do SPI] também é dado à prática de castigar fisicamente índios, espancando-os e pondo-os dentro de uma cisterna cheia de escrementos humanos, durante uma noite inteira no Pôsto Ivair. (Depoimento de Samuel Brasil, em 04/11/1967, RF, v. 9, p. 1720).

O tronco é um instrumento comum utilizado como domesticação dos corpos. Taussig (1993), ao tratar sobre o terror na realidade colonial, observa que o tronco é o instrumento primordial da tortura. No contexto 
colonial da economia da borracha na região do Putumayo (Amazônia colombiana), estudado pelo autor, ele destaca três formas de controle sobre o corpo: o trabalho forçado associado à dívida compulsória; o concubinato com jovens mulheres indígenas; e a aquisição de crianças indígenas pela força, troca ou compra/venda. As correrias, a escravidão e o endividamento eram elementos-chave para pensar e conceber as narrativas e as imagens da selvageria, representando o abandono que se considera valores da civilização.

Das e Poole (2008) - ao analisar as práticas e políticas que moldam, regulam e disciplinam o que se considera como "estado" - propõem a produção de corpos distintos, passíveis de serem assassinados. Em outro trecho da Síntese do Relatório, Jáder destaca o que ele chama de "orgias predatórias" e essa predação se inscreve não apenas no roubo do patrimônio indígena, mas também dos seus corpos:

Encontramos um índio preso, cujo dorso, riscado de muitas cicatrizes longas indicava serem resultado de chicotadas. Instado a responder, o desgraçado demonstrou verdadeiro pânico e não declarou a origem das cicatrizes" (RF, Síntese, p. 4918).

É nesse sentido que o ato de classificar os indígenas também significa demarcar corpos marginais, passíveis de serem torturados e explorada a sua força de trabalho, neste caso com a prática da Renda Indígena, como será visto a seguir.

\section{A Renda Indígena, trabalho forçado e burocracia na produção social da indiferença}

A Renda Indígena é uma das práticas estatais na qual se observa claramente as relações de poder e a concretização da violência contra os povos indígenas. De certo modo, ela congrega a esse conjunto de ações de controle e gestão (aparentemente improvisada, segundo alguns depoimentos e declarações) os deslocamentos forçados de indígenas e o controle de terras no mercado da madeira e da pecuária. Ela se tornou, de acordo com Freire (2009), uma das principais atividades econômicas características do SPI a partir dos anos 40 . Mais tarde, foi instituída por 
meio da Lei $\mathrm{n}^{\circ} 6.001$, em 19 de dezembro de 1973, conhecida como o Estatuto do Índio. Conforme o Artigo 43:

A renda indígena é a resultante da aplicação de bens e utilidades integrantes do Patrimônio Indígena, sob a responsabilidade do órgão de assistência ao índio.

$\S 1^{\circ} \mathrm{A}$ renda indígena será preferencialmente reaplicada em atividades rentáveis ou utilizada em programas de assistência ao índio.

$\S 2^{\circ}$ A reaplicação prevista no parágrafo anterior reverterá principalmente em benefício da comunidade que produziu os primeiros resultados econômicos. (BRASIL, 1973)

A partir da leitura desta lei de modo contextualizado e do Relatório Figueiredo, é possível observar como a violência, enquanto construção histórica e cultural, está imbrincada nas diversas modalidades de "gestão de populações", conforme Foucault (2008). De modo que não se governa um estado, um território ou uma estrutura política, mas pessoas e coletividades. Essa concepção de gestão e governo de populações disciplina e modifica o espaço, impõe modos de viver e cria estereótipos a respeito dos povos indígenas, bem como reforça a ideia principal do projeto de nação: civilizar regiões consideradas inóspitas e habitadas por tipos que não correspondiam ao modelo de nação brasileira.

A Renda Indígena foi brutalmente desviada do seu caráter original (se de fato em algum momento foi pensada para o benefício dos indígenas), visto que o SPI durante seus anos de gestão fez aplicações e utilizações provenientes da mão de obra dos indígenas e a remoção forçada dessas populações de suas terras. Roberto Cardoso de Oliveira (1978), em seu clássico artigo intitulado "Indigenismo ou colonialismo?", já destaca a problemática relação de patronagem, a qual a prática da Renda Indígena está intimamente associada, bem como ao colonialismo interno. Para o autor,

a economia tribal, especificamente aquela que não esteja limitada à mera subsistência e que, portanto, se destina à produção para o mercado está submetida a um regime de "patronato". Esteja ela organizada em base agrícola, extrativa ou pastoril, a direção está nas mãos do encarregado do Posto Indígena e as rendas auferidas são contabilizadas em nome do Serviço de Proteção aos Índios sob o título de Renda Indígena. Essa renda é 
constituída da venda de gado, madeira, borracha, diferentes culturas como o milho e o arroz, etc., canalizada dos Postos Indígenas às Inspetorias Regionais e, desta, à Diretoria Central, em Brasília. Sua redistribuição é feita segundo critérios os mais variados: pode retornar (e isso parcialmente) ao Posto que a produziu, pode ser aplicada em Postos indígenas que nada produziram, pode ainda financiar serviços administrativos ou técnicos nos Postos, nas inspetorias Regionais (localizadas, em regra, em capitais de Estados ou Territórios) ou na Diretoria. De um lado, isso significa que a "ação indigenista" pretende ser auto-financiável, num visível escamoteamento de suas reais finalidades assistenciais e que resulta ser uma modalidade refinada de colonialismo interno: a cobrança indireta de taxas ou impostos pela transformação do trabalho indígena ou de seu patrimônio econômico nos agentes financiadores das práticas assistenciais e protetoras... De outro lado, estando a destinação dessa Renda programada para o conjunto da população indígena, teoricamente de conformidade com as necessidades específicas de cada grupo silvícola em particular, isso representa sobrecarga injusta que recai exatamente naqueles grupos ou territórios tribais que maior produção logram alcançar (OLIVEIRA, 1978, p. 137).

Oliveira continua destacando o caráter das relações patrãoempregado, nas quais os encarregados dos Postos Indígenas se estabeleciam como patrões, enquanto os indígenas como empregados. Além disso, esses encarregados, em geral, eram recrutados entre os regionais, o que facilitava a incorporação e reprodução dessas relações de patronagem dentro do SPI. Neste caso, "os índios não são donos de sua produção, pois esta é comercializada pelo Posto Indígena, cujo objetivo essencial não é, seguramente, o bem-estar da comunidade silvícola sob sua supervisão, mas o incremento de uma produção destinada a ampliar a Renda Indígena em seu conjunto" (p. 138).

A produção e a receita provenientes do trabalho indígena variavam de acordo com a Inspetoria e administração regional. Conforme o depoimento de Luís de França Pereira Araújo, funcionário do SPI, em junho de 1963, a renda indígena:

compõe-se de resultados comerciais na atividade da agricultura, da indústria extrativa e algumas indústrias rudimentares e também da pecuária. (...) Tôdas elas 
[inspetorias] têm, dependendo da região. Umas têm mais de agricultura, outras, como nas regiões do norte, mais a indústria extrativa. (...) Há também os arrendamentos para exploração da própria terra, arrendamentos para pastagem. Isso existe (Depoimento de Luiz de França Pereira Araújo, em 06/06/1963. RF, v. 3, p. 491).

Em algumas inspetorias a Renda Indígena está intimamente ligada ao arrendamento das terras indígenas como no caso relatado por Walter Samari Prado, funcionário do SPI. Ao falar sobre o orçamento do SPI, relatou que

a inspetoria de Campo Grande não foi beneficiada por emendas. De fato, ela pode e deve dar melhor assistência àqueles índios, porque é a inspetoria considerada por nós das mais ricas ou talvez a mais rica do SPI, com rendas, apesar de não estarem legalizadas dentro da repartição, mas há anos vem obtendo recursos do arrendamento da Reserva dos Caiuéus. (...) Temos poucos dados na repartição sôbre isso. De maneira que devia haver melhor assistência, já que os recursos são grandes lá, com as rendas provenientes dos arrendamentos (Depoimento Walter Samari Prado, em $06 / 06 / 1963$. RF, v. 3, p. 510)

A arrecadação da Renda Indígena também pode ser vista como um dispositivo (FOUCAULT, 2000) de controle, tutela e violência contra os povos indígenas no Brasil. $\mathrm{O}$ dispositivo consiste em:

um conjunto decididamente heterogêneo que engloba discursos, instituições, organizações arquitetônicas, decisões regulamentares, leis, medidas administrativas, enunciados científicos, proposições filosóficas, morais, filantrópicas. Em suma, o dito e o não dito são os elementos do dispositivo. O dispositivo é a rede que se pode tecer entre estes elementos (FOUCAULT, 2000, p. 244).

Se tomarmos esta definição para pensar a atuação do SPI, por meio de uma prática específica, que engloba uma rede de mecanismos de violações de direitos humanos, estendendo-se desde a espoliação de terras, exploração do trabalho, deslocamentos forçados, até torturas, dentre outros, podemos observar que a partir de uma política estatal com legislação específica, esta prática de arrecadação de verba incorporada ao 
orçamento do SPI se caracterizou não apenas como uma corruptela do Sistema de Proteção aos Índios, mas também como um modo de marginalizar pessoas por meio do trabalho análogo à escravidão, a partir do que preconiza Herzfeld (2016) como uma "produção social da indiferença", estabelecida pela burocracia estatal.

Neste sentido, a burocracia se configura enquanto armadilhas para a espoliação, a marginalização e a constituição de sujeitos tutelados pelo Estado. No sistema burocrático, afirma Herzfeld (2016), os marginalizados são considerados fracassados, menores, e a produção social da indiferença ocorre a partir de um contexto burocrático no qual "a indiferença é a rejeição da humanidade comum. É a negação da identidade, da individualidade". E isso, dentre outras coisas, culmina com a perspectiva da vitimização do sujeito, de despolitização do sofrimento dessas pessoas.

Herzfeld (2016) percebe que, no contexto burocrático, a mentalidade burocrática parte "do mesmo discurso da prestação de contas, da pessoalidade e da força superior. Enquanto as pessoas culpam os burocratas, os burocratas culpam o 'sistema', as leis, o 'governo'”. Ele observa ainda que "nas leis promulgadas pelas mais benignas democracias oculta-se a possibilidade de repressão burocrática" (p. 16). Deste modo, nos aconselha: "devemos examinar criticamente como aqueles que estão no poder usam os símbolos e a retórica existentes para produzir determinismos tão perniciosos" (p. 55), algo que foi observado no trecho do Estatuto do Índio, destacado acima. O que confirma a máxima: a retórica do "bem comum" nem sempre serve ao bem comum.

Pode-se constatar a má fé de administradores e funcionários da infeliz repartição, que procediam com tanta irresponsabilidade no trato dos dinheiros públicos e dos recursos oriundos da renda indígena, causando, como testemunhamos, permanente estado de alerta entre os auditores designados para o exame da documentação comprobatória das despesas (Relatório Figueiredo Síntese, p. 4921)

Pozzobon (1999), num ensaio bastante crítico sobre a Fundação Nacional do Índio (Funai), aponta os diversos aspectos do funcionamento problemático da instituição. Muitos desses aspectos, o autor considera como heranças do SPI, como, por exemplo, a disputa interna dos 
servidores, o assistencialismo - que se desdobra na manipulação, acobertamento da incompetência, desvio de verba e exploração ilegal das áreas indígenas - e a, consequente, marginalização dos povos indígenas. A falta de orçamento viável alimentava a engrenagem da Renda Indígena, cujos recursos eram desviados pelos funcionários. Segundo o autor, a "política genocida dos militares" era criticada, mas logo os críticos se aliavam aos funcionários fisiológicos da instituição, dando continuidade às práticas do SPI.

Jáder de Figueiredo destacou ainda na Síntese do Relatório que o SPI se caracterizava como um "antro de corrupção inominável durante muitos anos" (RF Síntese, p. 4912), que reproduzia o regime de escravidão, com funcionários públicos que negavam o mínimo de condições dignas de vida para os indígenas e que praticavam torturas e suplícios como "instrumentos de justiça".

As estratégias de enfrentamento, seja no contexto da Ditadura seja no atual contexto de gestão de territórios, ocorrem a partir do pertencimento e do engajamento político de cada povo, mesmo estando organizado em instituições únicas, que se adaptam aos discursos burocráticos ocidentais para resguardar seus direitos. A perspectiva da vitimização dos sujeitos não pode ser considerada única nesta configuração histórica e social. A autonomia é acionada constantemente por meio da resistência aos atentados e às ameaças, relativizando esse papel social de vítima preestabelecido e da tutela como um fantasma a assombrar a prática para a emancipação. Autonomia implica resistência à aceitação do autoritarismo, que vai determinar até a disciplina corporal e social nos modos de ser.

\section{Algumas considerações finais}

Durante as discussões para produção deste texto, tomamos o cuidado de não personalizar a responsabilidade das atrocidades cometidas pelo Estado contra os povos indígenas durante o período da ditadura. Tal cuidado também nos guiou no caminho de uma escrita sobre o terror na situação colonial, na sua mais cruel versão. As críticas apontadas por Oliveria (1978) e Pozzobon (1999) demonstram um projeto 
de construção de nação falido em termos de gestão de populações. Esse projeto se caracteriza pela dinâmica de normalização da violência, como observou Feldman (2002), ao discutir sobre o distanciamento e a despersonalização das vítimas das atrocidades do Estado no contexto sul-africano. Para o autor, a economia política da violência, a partir do consumo e da comensalidade de corpos de cor, constitui a sustentação do terror político.

Assim como as práticas de tortura na África do Sul preconizavam a despersonalização e a bestialização da personalidade das vítimas, a experiência da ditadura, com a animalização dos povos indígenas, também preconiza a organização e a institucionalização estatal da violência em suas diversas facetas: seja no assistencialismo, paternalismo, patronagem ou tortura, a origem da violência é comum. Nesse sentido, o Estado em sua manifestação opressiva, no caso da ditadura, se utiliza da violência para domesticar, docilizar e pacificar os corpos indígenas na tentativa de silenciamento e homogeneização desses povos.

No entanto, essas práticas não foram capazes de silenciar os indígenas, que ressignificam, reinventam e resistem a mais de quinhentos anos de opressão. $O$ ideal de branqueamento do povo brasileiro, por sorte e muita luta dos povos indígenas, não ocorreu. Atualmente, vivemos um momento político marcado por um novo golpe (cinquenta e dois anos após o golpe civil militar) e acompanhamos a pré-candidatura de uma mulher indígena como vice-candidata à presidência da república. Isto demonstra que apesar das atrocidades e do genocídio e entocídio sistemático empreendidos contra os povos indígenas, eles se organizam e representam, de certo modo, a força democrática que o Brasil parece estar distante de compreender.

Referências bibliográficas

AZOLA, F. A. A.; LIMA, E. C. Entrevista com Marcelo Zelic: sobre o Relatório Figueiredo, os indígenas na Comissão Nacional da Verdade e a defesa dos Direitos Humanos. Mediações - Revista de Ciências Sociais, Londrina, v. 22, n. 2, p. 347-365, 2017. 
BAZIN, Jean. Des clous dans la Joconde: l'anthropologie autrement. Toulouse: Anacharsis, 2008.

BLOK, Anton. Honor and violence. United Kingdom, Polity, distributed by Blackwell, 2001.

BRASIL. Ministério da Agricultura, Indústria e Comércio. Relatório apresentado ao Presidente da República dos Estados Unidos do Brasil pelo Ministério da Agricultura, Indústria e Comércio Dr. Pedro Toledo no anno de 1911, v. I e II. Rio de Janeiro: Officina da Directoria Geral de Estatística, 1911.

Ministério do Interior. Relatório da Comissão de Inquérito Instaurada pela Portaria $n^{0}$ 154, de 24 de julho de 1967, Brasília, 1967. Disponível em: $<$ http://www.docvirt.com/docreader.net/DocReader.aspx ?bib=DocIndio\&PagFis=103>. Acesso em 10 mar. 2017.

Lei $\mathbf{n}^{0}$ 6.001, de 19 de dezembro de 1973. Dispõe sobre o Estatuto do Índio. In: Diário Oficial da República Federativa do Brasil, Brasília, 21 dec. 1973. Disponível em: <http://www.planalto.gov.br/ccivil_03/leis/16001.htm>. Acesso em 15 jan. 2016.

BRIGHENTI, Clovis Antonio. Colonialidade do poder e a violência contra os povos indígenas. Revista PerCursos, Florianópolis, v. 16, n. 32, p. 103-120, set./dez. 2015

CARDOSO DE OLIVEIRA, Roberto. O índio e o mundo dos brancos. Campinas: Editora da Unicamp, 1996.

CUNHA, Manuela Carneiro da; FARAGE, Nádia. "Caráter da tutela dos índios: origens e metamorfoses”. In: CUNHA, M. C. Os direitos dos índios: ensaios e documentos. São Paulo: Brasiliense, 1987.

DAS, Veena; POOLE, Deborah. El estado y sus márgenes. Etnografías comparadas. Cuadernos de Antropología Social, n. 27, p. 19-52, 2008. Disponível em: <http://www.scielo.org.ar/pdf/cas/n27/n27a02.pdf $\geq$. Acesso em 20 dez. 2015.

ELIAS, Norbert. Os alemães: A luta pelo poder e a evolução do habitus nos séculos XIX e XX. Rio de Janeiro: Jorge Zahar, 1997.

FELDMAN, Allen. Strange Fruit: The South African Truth Commission and the Demonic Economies of Violence. In: Beyond rationalism: rethinking magic, witchcraft and sorcery. New York: Barghahn books, 2002.

FOUCAULT, Michel. Microfísica do poder. Rio de Janeiro: Graal, 2000.

Segurança, território e população. São Paulo: Martins Fontes, 2008.

FREIRE, Carlos Augusto da Rocha. O SPI na Amazônia: políticas indigenistas e conflitos regionais 1910-1932. 2. Ed. Rio de Janeiro: Museu do Índio, 2009. 
GUIMARÃES, Elena. Relatório Figueiredo: entre tempos, narrativas e memórias. 2015. 204 f. Dissertação (Mestrado em Memória Social) - Programa de Pós-Graduação em Memória Social. Universidade Federal do Estado do Rio de Janeiro, Rio de Janeiro, 2015 .

HERZFELD, Michael. A produção social da indiferença: explorando as raízes simbólicas da burocracia ocidental, Petrópolis: Vozes, 2016.

MATTEI, Ugo; NADER, Laura. Pilhagem: quando o Estado de Direito é ilegal. São Paulo: Martins Fontes, 2013.

OLIVEIRA, Roberto Cardoso de. Indigenismo ou colonialismo? In: A sociologia do Brasil indígena. Rio de Janeiro: Tempo brasileiro; Brasília: Editora UnB, 1978.

OLIVEIRA FILHO, João Pacheco de. Pacificação e tutela militar na gestão de populações e territórios. Mana, Rio de Janeiro, v. 20, n. 1, p. 125-161, abr. 2014. Disponível em: <http://dx.doi.org/10.1590/S0104-93132014000100005>. Acesso em 15 jan. 2015.

POZZOBON, Jorge. O lumpen-indigenismo do estado brasileiro. In: Journal de la Société des Américanistes. Tome 85, 1999. p. 281-306. Disponível: https://www.persee.fr/doc/jsa_0037-9174_1999_num_85_1_1738. Acesso em 15 de mar 2016.

SALGADO, G. (org.). Fiscais e meirinhos. Rio de Janeiro: Nova Fronteira, 1985.

SOUZA LIMA, Antônio Carlos de. Um grande cerco de paz: poder tutelar, indianidade e formação do Estado no Brasil, 1995.

Sobre tutela e participação: povos indígenas e formas de governo no Brasil, séculos XX/XXI. Mana, Rio de Janeiro, v. 21, n. 2, p. 425-457, ago. 2015. Disponível em: 〈http://www.scielo.br/pdf/mana/v21n2/0104-9313-mana-21-02-00425.pdf>.

. Reconsiderando poder tutelar e formação do Estado no Brasil: notas a partir da criação do Serviço de Proteção aos Índios e Localização de Trabalhadores Nacionais. In: FREIRE, Carlos Augusto da Rocha (org.). Memória do SPI: textos, imagens e documentos do Serviço de Proteção aos Índios (1910-1967). Rio de Janeiro: Museu do Índio/Funai,, 2011. p. 201-2011

SAMPAIO. Patrícia M. Fronteiras da liberdade: tutela indígena no Diretório Pombalino e na Carta Régia de 1978. In: LIMA, Antonio Carlos de Souza (org.). Tutela: formação de Estado e tradição de gestão no Brasil. 1ed. Rio de Janeiro. E-papers, 2014.

TAUSSIG, Michael. Xamanismo, colonialismo e o homem selvagem: um estudo sobre o terror e a cura. Rio de Janeiro: Paz e Terra, 1993.

VALENTE, Rubens. Os fuzis e as flechas: história de sangue e resistência indígena na ditadura. Companhia das Letras. $1^{a}$ ed. São Paulo, 2017. 
